\title{
Percepción de las funciones testiculares no reproductivas antes de la testosterona: mitos y realidades
}

\author{
Perception of Non-reproductive Testicular Functions Before Testosterone: \\ Myths and Facts
}

Jácome A.

Internista-Endocrinólogo, miembro honorario de la Asociación Colombiana de Endocrinología, Diabetes y Metabolismo, miembro de número de la Academia Nacional de Medicina y de la Sociedad Colombiana de Historia de la Medicina. Editor Emérito, revista Medicina, Bogotá.

Fecha de recepción: 26/03/2019

Fecha de aceptación: 29/03/2019

\section{Resumen}

Desde tiempos inmemoriales, la humanidad conocía el efecto de la castración sobre animales y hombres, sabía que el animal castrado era más fácil de controlar, que los eunucos no podían embarazar y que si el procedimiento se realizaba antes de la pubertad, se conservaba la voz atiplada. Dicha práctica fue común en algunos países orientales, buscando objetivos políticos y socioculturales. La deficiencia de testosterona se convirtió en esas regiones en la principal alteración endocrina.

En tiempos modernos, médicos y científicos trataron de aclarar el panorama. Se conoció en detalle la anatomía de los genitales masculinos y la histología testicular (túbulos seminíferos, células de Leydig y las de Sertoli). Berthold hizo un experimento pionero que demostró en gallos capones la recuperación de sus características de macho con injertos de testículo. Brown-Séquard afirmó haberse rejuvenecido gracias a que se inyectó un líquido a base de extracto testicular, lo que causó revuelo mediático y críticas de otros académicos, ya que era un reconocido científico. Se popularizaron entonces, tanto la opoterapia como los tratamientos rejuvenedores a base de implantes testiculares, que generaron dinero a una serie de charlatanes. Pero en los años treinta se logró aislar y sintetizar los esteroides sexuales, entre ellos la testosterona, recuperando este campo para la ciencia.

Palabras clave: testosterona, andrógenos, castrados, historia, endocrinología.

\section{Abstract}

Mankind was aware of castration effects upon men and animals since antiquity. People knew that castrated animals were easier to control, that eunuchs were not able to make women pregnant and that people remained with a high-pitched voice when the procedure waas done before puberty. With political and socio-cultural objectives, mostly in eastern but also in some european countries, this practice was common. Testosterone deficiency was therefore prevalent.

In modern times, physicians and scientists made some findings that clarified a few things. Anatomy of male genitalia and histological studies of the testes demonstrated seminiferous tubules, interstitial and Sertoli cells. Berthold undertook a pyoneering experiment, showing that castrated (capon) roosters recovered lost male characteristics by testicular grafts. Brown-Sequard, in spite to be a recognized scientist, published a paper with subjective statements about him and his wife rejuvenated a lot thanks to injections of liquid testicular extracts, shaking media and getting severe criticism from other academicians.

Testicular opotherapy and rejuvenation surgical implant procedures became popular and made wealth to a number of quacks. But in the thirties, isolation and synthesis of sexual steroids including testostere, recovered this field for science.

Key words: testosterone, androgens, castrated, history, endocrinology.

\section{Introducción}

Desde la antigüedad se relacionaba al testículo con la fecundación y con la capacidad sexual. También se había usado la organoterapia, mas no con la idea de que hubiera sustancias activas en las vísceras sino en la creencia de que un órgano enfermo podía ser curado por la ingestión del mismo órgano, pero sano. Así los egipcios prescribían molido de pene de asno 
para curar la impotencia, y los romanos -tal vez mejor encaminados- recomendaban testículos del mismo animal para curar la afección. En los antiguos campeaba el pensamiento mágico y creían que una planta medicinal era más eficaz con la adición de los $\operatorname{rezos}^{(1)}$.

\section{La Antigüedad}

Entre 2737 y 1600 a. C., en el Pen Tsao (gran herbario) se recomendaba el uso de semen de hombres jóvenes para el tratamiento de la disfunción eréctil. El taoísmo creía que la esperma venía del cerebro. La Biblia habla de castrados y eunucos y el Talmud usa el nombre de "testículo" para las gónadas de los dos sexos y describe casos de hermafroditas. Hipócrates en el siglo V a. C. escribió "la semilla” y habló de la inflamación testicular en casos de paperas, lo que llevaba a infertilidad. En el siglo IV a. C., Aristóteles, filósofo interesado en la naturaleza, escribió sobre el semen, considerándolo el agente formativo o activante o 'alma", mientras que el elemento femenimo era el suelo pasivo que sería fertilizado. Creía este griego que había una diferencia entre los dos testículos, ya que el semen proveniente del derecho originaba fetos masculinos y el del izquierdo, femeninos ${ }^{(2-5)}$.

\section{La castración}

El eunucoidismo (hoy llamado hipogonadismo) -cuadro que se desarrolla por la castración- ha sido conocido en todas las épocas y regiones. Eunuco -que quiere decir guardián de lecho- es una palabra mencionada en muchos libros antiguos como la Biblia. Y, nuevamente, Aristóteles dice que lo que le ocurre al gallo capón y al hombre castrado es que "la cresta del gallo se vuelve pálida, ya no canta más y abandona sus actividades sexuales, características que nunca aparecen si la castración se realiza antes de su juventud... tal como pasa en el hombre, que -castrado antes de su pubertad- no le aparece vello y su voz se mantiene atiplada..."(3).

Entre los chinos y orientales el asunto era algo tradicional; un autor de nombre Matignon dice que "en China se es eunuco por la fuerza, por gusto, por pobreza y por pereza".
Tabla 1. Objetivos de la castración

- Realizar un castigo (en la Escandinavia medieval cegaban y castraban a sus enemigos para no matarlos).

- Preservar el celibato y la castidad (como entre los cátaros, secta herética en el sur de Francia o en la secta escóptica, en el sur de Rusia). Se habla de la automutilación de Orígenes, uno de los primeros Padres de la Iglesia).

- Conservar voces de soprano(6,7) en hombres adultos, (como en los castrati italianos que actuaban en coros y en óperas) (figura 1).

- Obtener eunucos como guardianes de los harenes o servidores leales (China y Turquía), o para realizar trabajos pesados (esclavos subsaharianos) $)^{(8,9)}$.

Durante milenios se utilizó la castración deliberada con objetivos políticos y socioculturales; la automutilación se usó por razones religiosas (tabla 1). Actualmente se realiza en el tratamiento del cáncer de próstata y en la cirugía para los transgeneristas; también, la castración química para violadores en serie.

Las castraciones en muchos casos eran verdaderas emasculaciones (llamadas "gran sello", cuando se cortaban tanto los testículos como el pene) pero en otros casos eran solo

Figura 1. Caricatura de dos famosos castrati italianos, una mujer en medio, y atrás un enano. El hipogonadismo prepuberal de estos famosos cantantes muestra su estatura y largas extremidades ${ }^{(6,7)}$

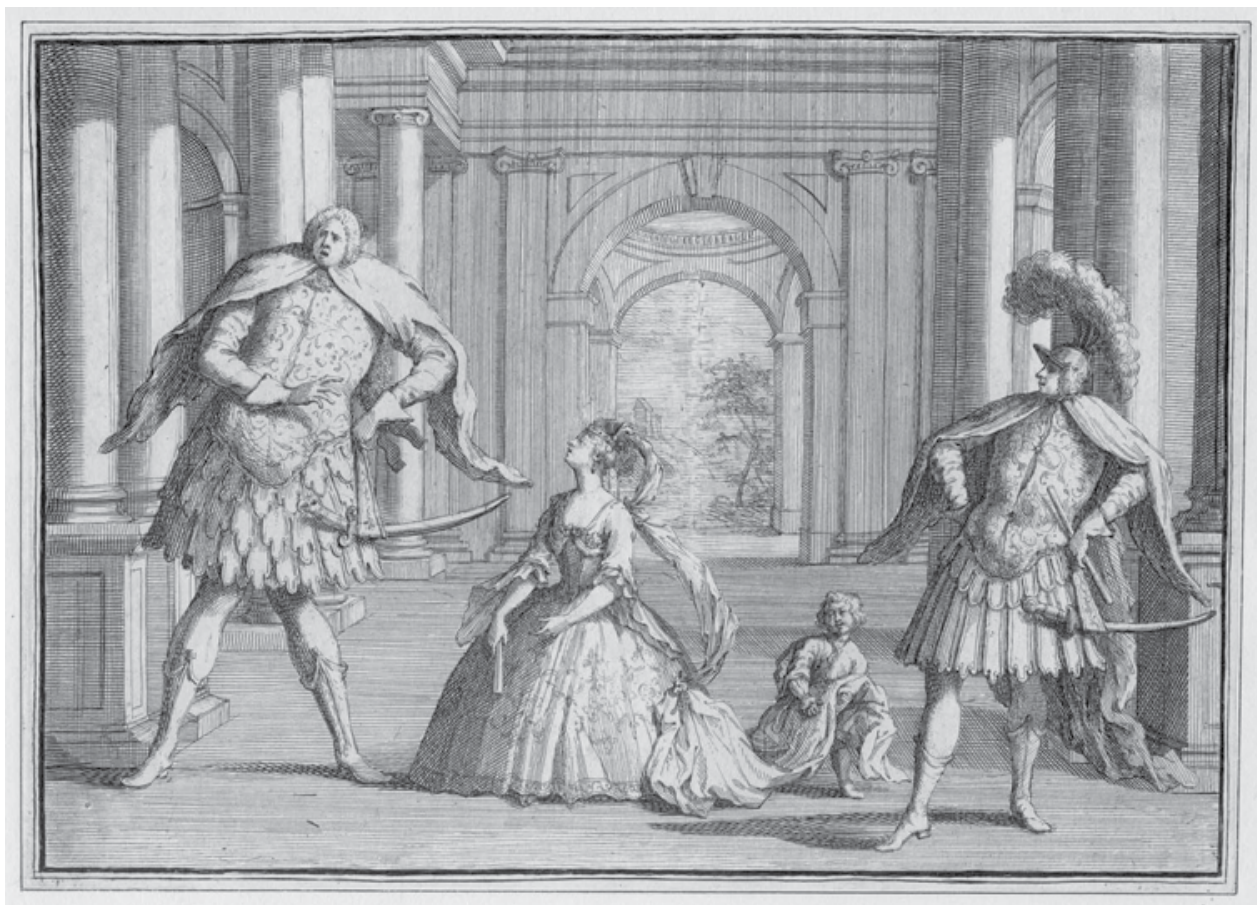


las gónadas (o "pequeño sello"), lo que a veces permitía una actividad sexual limitada. Se han realizado revisiones muy completas de la perspectiva histórica del hipogonadismo por castración, como la de los esposos Niechslag ${ }^{(8)}$, otra de J.D. Wilson $^{(9)}$ y la de nuestro compatriota y compañero de la Javeriana, el profesor de urología de Toronto, Álvaro Morales Gómez ${ }^{(10)}$. El comentario de la doctora Wilson ${ }^{(9)}$ además revisa los seis únicos estudios que hay acerca del efecto a largo plazo sobre la castración en eunucos escópticos, chinos y otomanos, como el agrandamiento de la hipófisis, los cambios esqueléticos (falla en el cierre epifisiario, osteoporosis), ginecomastía y la "aparente” desaparición de la próstata; trae también una importante colección de fotografías de eunucos.

\section{Después de Cristo hasta el siglo XVIII}

Plinio El Viejo recomendaba la ingestión de testículos animales para la impotencia. Areteo de Capadocia enseñaba que era la esperma la que convertía al prepuber en hombre. Mesue El Viejo, medico árabe, prescribía la ingesta de testículos como afrodisiaco, y en el tratamiento de la tuberculosis pulmonar, asumimos que para combatir la caquexia. San Alberto Magno, interesado también en las ciencias de la naturaleza, recomendaba testículos de cerdo en polvo, disueltos en vino, para tratar la debilidad sexual masculina ${ }^{(2)}$.

A comienzos del segundo milenio, el chino Hsu Shu-Wei usaba testículos desecados de cerdo para tratar la espermatorrea, el hipogonadismo y la impotencia. Para esta época, debido a que se recomendaba beber orina para la impotencia, yatroquímicos chinos evaporaban grandes volúmenes de orina y luego procedían a la sublimación del sedimento para que lo ingirieran los príncipes, evitando el mal sabor. Hoy se sabe que con la sublimación a altas temperaturas, los esteroides sexuales pasan al aire sin cambios en su estructura ${ }^{(3)}$.

Thomas Willis planteó que la sangre recibía un fermento especial de las venas espermáticas ${ }^{(1)}$. En 1775, Teófilo de Bordeu afirmó que la gónada masculina producía una secreción interna, pero que según él era idéntica al semen. Los escritos de este francés lo ubican como uno de los precursores de la endocrinología ${ }^{(2)}$.

El famoso anatomista y cirujano escocés John Hunter (1728-1793), fundador de un exitoso museo de medicina que lleva su nombre, participó en esta epopeya que ahora narramos, con sus experimentos de injertos testiculares de gallo en abdómenes de gallinas, los primeros que fueron exitosos en cuanto a que se adaptaron al nuevo ambiente, con formación de vasos y redes nerviosas a su alrededor. Debido a que John Hunter no escribió artículos especiales sobre estos experimentos en particular, lo que se encuentra o lee entre líneas en sus conferencias es lo que recibe una interpretación de los historiadores. No sabemos qué pasó con las gallinas, aunque el propósito de Hunter era observar la viabilidad del injerto y estudiar las propiedades del llamado "principio vital". No es claro si realizó un estudio sobre la recuperación del gallo capón injertado con testículo de otro gallo como algunos afirman, cosa que sí demostró Berthold, 80 años más tarde $\mathrm{e}^{(3,8-10)}$.

Para aquella época, la influencia positiva de un órgano sobre otro se llamaba "simpatía", y en el caso de los testículos y las características sexuales secundarias, esta simpatía sería "remota". Hunter también estudió los casos de terneras incapaces de reproducirse por la acción androgénica de gemelos machos, a las cuales se les atribuye un trastorno genético llamado "quimerismo"(3).

La época en la que se conocería el funcionamiento de las glándulas de secreción interna -a partir de los signos asociados con sus patologías- se demoraría muchas décadas más en llegar. Antes de los informes ochocentistas acerca de experimentos y enfermedades relacionados con los órganos encargados de las secreciones internas, existían ya algunos datos inconexos acerca de las glándulas sin conducto e incluso algunas hipótesis que intentaban encontrar explicaciones teóricas sobre un sistema en ciernes. No se relacionó, sin embargo, la anatomía con las enfermedades y terapias de órganos, pues de haberlo hecho, la medicina habría progresado más rápidamente.

\section{Histología testicular}

El descubrimiento del microscopio profundizó los estudios anatómicos. Jean Riolan, el joven, describió en 1626 los túbulos seminíferos y, medio siglo después, Leeuwenhock y Ham descubrieron los espermatozoides. En 1651, Highmore describió el mediastino testicular, tejido fibroso que contiene la rete testis la que fue descrita en detalle un siglo después por von Haller.

Regnier de Graaf, holandés nacido en 1641, hizo numerosos aportes a la medicina durante su corta vida de 32 años. Aunque es más conocido por los estudios sobre el ovario y el "folículo maduro de De Graaf", también investigó acerca del testículo en 1668, antes de sus descripciones sobre el ovario. Escribía con muy buen latín y en su libro Tractatus de virorum organis generationi inservientibus informó que el testículo contenía fundamentalmente túbulos seminíferos y no era una glándula como se conocía en aquellas épocas. De Graaf llamaba al ovario "el testículo femenino", sobre el que escribió bastante; le asignaba, sin embargo, una función reproductiva correcta pues debían "regar el útero a la manera de un jardín, para que el suelo sea fértil y el semen masculino pueda germinar"(3).

Spallanzani (1780) llevó a cabo procedimientos de inseminación artificial en animales. Astley Cooper escribió un libro en 1830 con sus observaciones (macroscópicas) acerca de la estructura y las enfermedades del testículo, refiriéndose principalmente a quistes y a tumores malignos ${ }^{(2)}$. 
Figura 2. Franz von Leydig, descubridor de las células intersticiales del testículo, donde se produce la testosterona

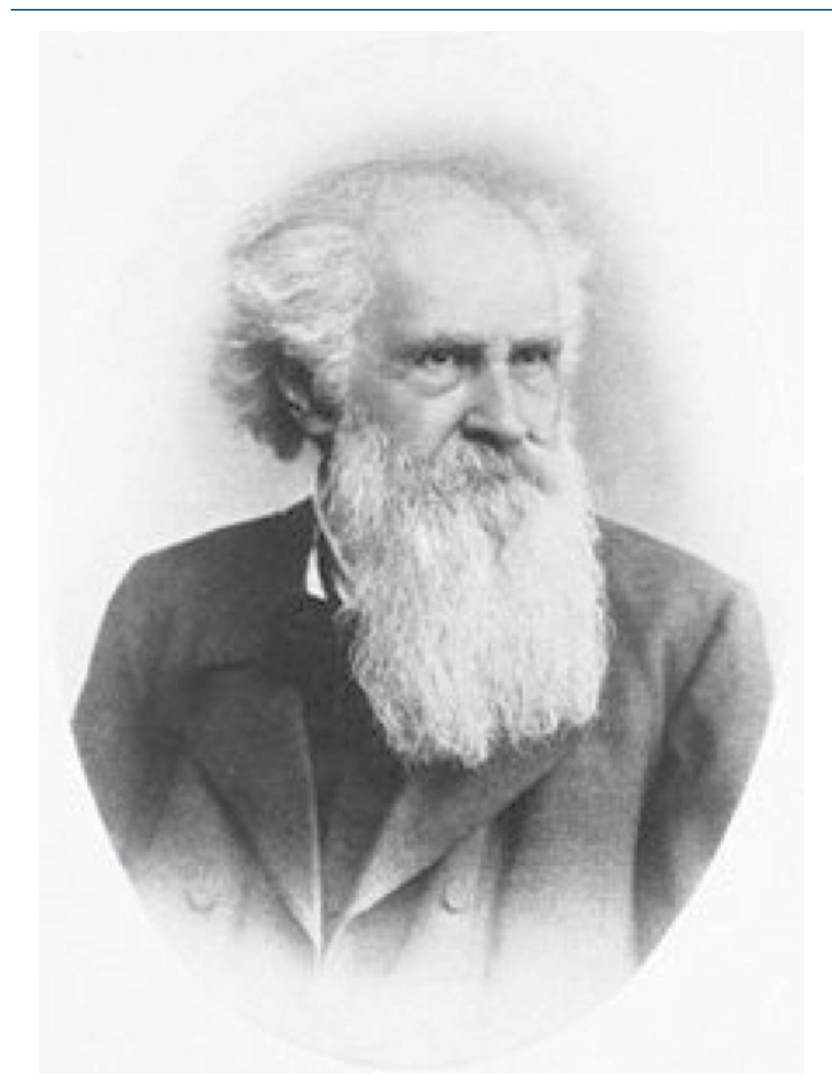

En 1850, Franz von Leydig( ${ }^{(1)}$ describió las células intersticiales en animales (figura 2). Fue un médico y zoólogo, profesor de Anatomía Comparada en varias universidades alemanas. Fue autor de numerosos estudios en crustáceos y peces, y en un detallado estudio de los órganos sexuales masculinos, Leyding escribió lo siguiente: "Los estudios comparativos de los tejidos permitieron el descubrimiento de unas células que rodean los túbulos seminíferos, vasos y nervios. Estas especiales células están presentes en pequeños números, siguiendo el curso de los vasos sanguíneos, pero que aumentan considerablemente su masa cuando rodean los túbulos seminíferos. Son de carácter lipídico, pueden no tener color o teñirse de un color amarillento, y tienen un núcleo vesicular claro".

Para el siguiente año, Albert von Kolliker -quien había investigado el desarrollo y la naturaleza de los espermatozoides y fue jefe de Leydig en Anatomía e Histología de la Universidad de Wurzburg- encontró células de Leydig en humanos. En 1865 el italiano Enrico Sertoli describió un tipo diferente de células testiculares, que eran epiteliales, altas, presentes en los túbulos. A sus puntas se anexan las espermátides hasta que se convierten en espermatozoides, por lo que algunos las han llamado "células sustentaculares". También está presente el tejido conectivo vascular y con las células de Leydig forman el tejido intersticial ${ }^{(1-3)}$.
En 1889, Lipschutz y Wagner encontraron células de Leydig insuficientemente desarrolladas en conejos eunucoides, atribuyendo a estas células la secreción interna del testículo. Para 1890, Reinke informó la presencia de cristaloides en las células de Leydig. En 1896, Eccole Sacchi publicó el caso de una pubertad precoz asociada a un tumor testicular de células intersticiales que fue operado ${ }^{(2)}$.

Los histofisiólogos Pol Bouin y Paul Ancel (entre 1903 y 1904) dedujeron el papel de las células de Leydig en la diferenciación fenotípica masculina. También mostraron -en conejos machos- que la ligadura de los conductos eferentes producía degeneración de los túbulos seminíferos pero estos animales mantenían sus características sexuales y el tejido intersticial se encontraba intacto, donde están las células de Leydig; seis años después encontraron el componente progestacional del ovario $^{(12)}$

\section{Experimento pionero de Berthold}

El naturalista, médico y zoólogo alemán Arnold Adolph Berthold (1803-1861) realizó en 1849 un experimento que, aunque pionero, fue opaco y de muy escaso impacto entre la comunidad científica, pues incluso él mismo le restó importancia (figura 3); él demostró que al castrar y trasplantar los testículos de gallo a la cavidad abdominal no se producían los síntomas deficitarios que se ven en el capón; habló de la influencia de su secreción en la sangre, y a través de ésta sobre el organismo en general. Cuando descubrió que la cresta del gallo es andrógeno-dependiente, Berthold se desempeñaba como curador del zoológico local; vio que después de la castración, la cresta se atrofia, desaparece la conducta agresiva del macho y pierde el interés en las gallinas. Pero lo más impor-

Figura 3. Arnold Adolph Berthold

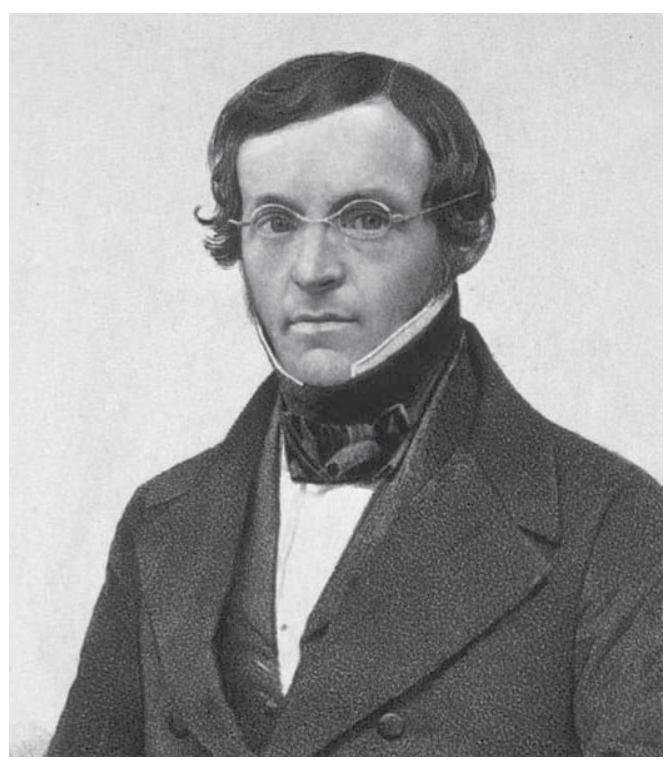

http://revistaendocrino.org/ 
tante fue el que pudiera revertir los cambios al administrar el extracto testicular crudo o hacer la reimplantación de la gónada; muchos consideran este experimento como el nacimiento de la endocrinología, aunque hemos visto que muchos de los datos ya conocidos sobre el tema permanecían inconexos, sin una hipótesis estructurada que se basara en resultados investigativos claros e incontrovertibles.

Poco tiempo después de su graduación como médico, Berthold fue director del museo zoológico de la Universidad de Gottingen, donde era profesor titular de la facultad de ciencias. Consejero real de la corte de Hannover y miembro de la Academia de Ciencias, publicó numerosos artículos científicos y un par de manuales. Es curioso que no se hubieran extrapolado estos hallazgos al experimento natural ampliamente conocido de los castrati italianos, que mostraban un cuadro clínico de hipogonadismo; o que no se basara en los escritos de Bordeu ocho décadas antes ${ }^{(10,13)}$.

\section{La opoterapia}

Ya en la segunda mitad del siglo diecinueve había fuertes controversias acerca de aquellos empíricos que se lanzaban a tratar con toda clase de medios una amplia variedad de patología, y aquellos -como Oliver Wendell Holmes- que creían que "el médico estaba para hacer diagnósticos, pronósticos y facilitar la recuperación de las enfermedades autolimitadas. En cuanto a la Materia Médica, bien podían tirarla al fondo del mar, para bien de la humanidad y desastre para los pobres peces"(1).

\section{El científico que termino estimulando la charlatanería}

Charles Edouard Brown-Séquard (1817-1894) fue básicamente un neurólogo experimental -endocrinólogo por casualidad-recordado en los textos de medicina por el síndrome (idealizado, pues en la clínica no se observa tan perfecto) de la hemisección medular que lleva su nombre; discípulo y sucesor de Bernard en la Academia, fue literato frustrado, obstetra, profesor del idioma gálico e ideólogo político. Brown-Séquard comprobó que la adrenalectomía experimental ocasiona la muerte de los animales; pero como dicha aseveración no pudo ser reproducida por otros, atribuyó entonces el fallecimiento de los animales a la gravedad de la intervención, es decir, que no se debía a una insuficiencia suprarrenal aguda completa y real. Antes del deceso, conejos, cobayos, perros y gatos -mas no las ratas- presentaban hipotensión,anorexia, adelgazamiento, astenia y pigmentación cutánea, como en la insuficiencia suprarrenal crónica en el hombre; luego se supo que las ratas tenían suprarrenales accesorias ${ }^{(14-17)}$.

Era un importante exponente de la medicina francesa, aunque también tenía origen americano y había nacido en Mauritania (figura 4). Él estaba convencido de que una serie de órganos -no solo los testículos- contenían secreciones que podrían ser
Figura 4. El gobierno de Mauritania expidió un estampilla en 1994 en recuerdo de Brown-Séquard

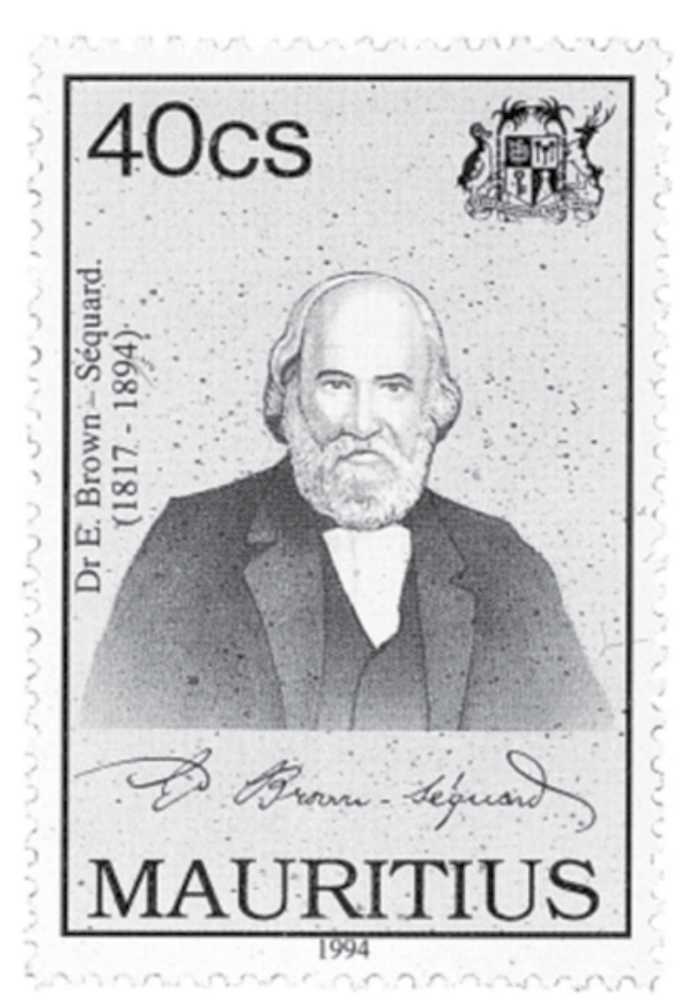

útiles para tratar enfermedades; había estudiado los efectos de la adrenalectomía en animales. Sugería lograr la revitalización de los viejos con jugos testiculares y hasta con la inyección intravenosa de semen o de sangre de la vena testicular desde décadas antes de su publicación final, por lo que venía siendo criticado.

Cuando, como adulto mayor, creyó que la administración de extracto testicular mejoraba a los conejos seniles, él y su esposa se lo autoadministraron, para luego informar en la Sociedad de Biología de París, el 1o. de junio de 1889 (a sus 72 años), acerca de los excelentes resultados. Según él, en aquel preparado estaba la fuente de la eterna juventud, ya que se había rejuvenecido ¡al menos 40 años!

Dicha experiencia fue publicada en Lancet, donde se describían de la siguiente manera los efectos rejuvenecedores de los preparados testiculares de perros y cobayos:

"El día después de haberme aplicado la primera inyección subcutánea -y aun más después de las siguientes dos- sentí un cambio radical... había recuperado cuando menos toda la fuerza que poseía muchos años antes... los resultados sobre la fuerza muscular fueron medidos - antes y después- con un dinamómetro... mejoró mi hábito intestinal... volví a mi anterior capacidad de trabajo intelectual, la que se había disminuido...”. También trató tres hombres en la tercera edad con extractos 
testiculares de conejo y cobayo con resultados igualmente dramáticos, mientras que otros dos que recibieron inyecciones de agua no tuvieron reacción alguna"(16).

La publicidad a este artículo no se hizo esperar, no porque se tratara de un estudio con una metodología científica, sino por el tema en sí -que favorecía el sensacionalismo- y por la gran fama del autor ${ }^{(14-16)}$.

\section{Nuevo auge de la opoterapia}

Antes de que acabara aquel año, ya había doce mil médicos que aplicaban el líquido de Brown-Séquard, varios químicos que se enriquecían con la fabricación del elíxir de la vida, y muchos galenos sin mayor formación que pusieron a sus pacientes en riesgo al administrarles sin más ni más -aprovechando la excitación del público- macerados o extractos de órganos de animales ${ }^{(1-3)}$. Se inició experimentación de la mala en humanos a torrentes, pues se inyectaban y trasplantaban estos testículos animales en patologías tan diversas como epilepsia, tuberculosis, diabetes, parálisis, gangrena, anemia, arteriosclerosis, influenza, enfermedad de Addison, histeria, migraña... ${ }^{(1)}$.

Aunque Brown-Séquard siguió creyendo que él había descubierto algo importante en el campo de la fisiología, en el cual era considerado un experto sí se mortificó mucho por lo ocurrido con la explosión de organoterapistas y de simples negociantes que encontraron una veta lucrativa en su publicación, que un tiempo después cayó en el desprestigio ante el escepticismo y desconcierto manifestado en muchas revistas científicas de la época; nadie podía creer que un numerario de la Sociedad Real Británica y de la Academia Francesa de Ciencias, que había realizado investigaciones de singular importancia en las principales ciudades de Europa y América, saliera con semejantes apreciaciones de tipo testimonial ${ }^{(14-16)}$. Años más tarde, Harvey Cushing, destacado neurocirujano y endocrinólogo, lo calificaría de "el Ponce de León" de nuestros predecesores médicos. Este colonizador español afirmó haber encontrado la fuente de la juventud, en San Agustín, La Florida.

\section{Ensayos exitosos}

Su erróneo mensaje originó, sin embargo, un interés en lo que sería la endocrinología; basta recordar a George R. Murray, quien, en 1891, logró resultados dramáticos en la recuperación de la fuerza muscular y el vigor intelectual, en un paciente con mixedema que fue inyectado por vía subcutánea con extracto fresco de tiroides de oveja ${ }^{(17)}$.

Esto hizo pensar a los académicos que sus investigaciones tenían importancia para su uso en la cama del enfermo, así que los casos de hipotiroidismo se empezaron a tratar con tiroides desecado y jarabe de rábano yodado, y el bocio endémico se empezaba a prevenir en Suiza, en 1920, con la adición de yodo a la sal de consumo humano, procedimiento que en Colombia se inició en $1950^{(18)}$.

\section{Famosos negociantes}

La costumbre de utilizar en terapéutica toda clase de órganos -incluso los endocrinos- tuvo como líder al doctor Henry R. Harrower (1883-1934), quien no sólo prescribía sino que fabricaba productos organoterápicos. No sólo ofrecía unos cuarenta órganos con sus correspondientes dosis e indicaciones, sino que respaldó dicha terapia con 67 artículos "científicos", tres libros y numerosas conferencias. Alguna vez almorzó con Osler, quien afirmó en esa ocasión -acudiendo a una analogía con un deporte muy norteamericano, el béisbol- que las secreciones internas serían el bate con el cual se impulsarían las carreras. El golpe mortal a la organoterapia se lo dio Harvey Cushing en 1921, quien inició una campaña contra estas verdaderas "sopas de mondongo"; cuando la literatura endocrina se volvió explosiva, Harrower intentó mantenerse al día con una teoría: la "homo estimulación", que tenía la ventaja de que el terapista no tenía que preocuparse por sobredosificar a los pacientes porque según el hambre de hormonas, el organismo solo tomaba lo que necesitaba y el resto lo excretaba; promovía entonces el uso masivo de preparados pluriglandulares, pues -según él- todas las enfermedades tienen algún componente de disfunción endocrina. Harrower era un empresario increíble, vigoroso e informado. Ante los nuevos descubrimientos, hacía concesiones pero siguió insistiendo hasta el final sobre la organoterapia ${ }^{(19)}$.

A Harrower se debe la fundación, en 1916, de la Asociación para el Estudio de las Secreciones Internas, pues visitó gran número de médicos particulares y muchos académicos, hasta conseguir una primera reunión. Esta agremiación evolucionó hacia la Endocrine Society actual, pero Harrower fue el fundador también de su revista Endocrinology. En sus comienzos, trabajó intensamente para dicha Asociación, pero años después sus colegas decidieron vetarlo, pues era ante todo un negociante y en el mundo académico existía una gran ola de escepticismo acerca de la actividad de hormonas administradas por vía oral, con excepción de los preparados de tiroides. En 1993 se fundó la Asociación Americana de Endocrinólogos Clínicos a partir de disidentes de la sociedad original, que estaban aburridos de tanta contemplación de la naturaleza (como podrían llamar a la investigación básica) y querían un poco más del arte de la práctica endocrinológica en enfermos ${ }^{(19)}$.

Además de Harrower, existieron otros negociantes de preparados organoterápicos supuestamente efectivos que tuvieron alguna fama: Fred Leach, de Chicago, a quien las autoridades postales no le prestaban el servicio por considerarlo un defraudador, John (glándula de cabra) Brinkley, que garantizaba la cura de la impotencia con la implantación de testículo de cabra o de estimular la líbido femenina con jalea real. Desde emisoras que tuvo en Kansas, y luego en México, hacía la propaganda de sus productos ${ }^{(20-22)}$.

La terapia celular fue promovida por el urólogo suizo Paul 
Niehans quien -como precursor teórico de las terapias con células madre- realizó más de cincuenta mil tratamientos en los cuales daba células del mismo órgano para la hipofunción y de órganos antagonistas para la hiperfunción. Utilizó toda clase de preparados endocrinos -particularmente de testículo- y entre sus pacientes famosos estuvieron el Papa Pío XII, Bernard Baruch y Aristóteles Onassis ${ }^{(1)}$.

Algunos laboratorios que existieron en Colombia en los años cuarenta fueron reconocidos por su opoterapia, entre ellos Labrapia (cuyos productos se denominaban órgano-cerebral, órgano-hepático, etc.) y Hormona, casa mexicana que se estableció en Colombia con inversiones locales de la familia Lleras, que tuvo a Carlos Lleras Restrepo como presidente de su Junta y que patrocinó durante años un recordado premio científico, el Federico Lleras Acosta. Llama la atención que en el vademécum PLM de 1944 que se volvió a editar para la conmemoración de los sesenta años de su primera publicación, entre los numerosos productos que anuncia el laboratorio Hormona en México pude contar no menos de 44 opoterápicos, la mayoría de "glándulas sin conducto" y que incluían extractos no solo gonadales sino de próstata, mama, epífisis, placenta, timo, paratiroides, y una curiosa hormona antitiroidea, llamada "Tirofen". Para los "trastornos neurovegetativos de la mujer con hipertiroidismo" tienen el "poliglandín femenino antitiroideo" que contiene extracto de glándulas frescas (ovario, mama, timo, suprarrenal) más foliculina y más "hormona antitiroidea". Semejante menjurje opoterápico se recomienda dar "entre una y tres grageas tres veces al día, junto con una dieta lactovegetariana". Laboratorios Hormona en Colombia fue posteriormente adquirido por la casa Ayerst, que luego se fusionó con Wyeth, una empresa farmacéutica americana que finalmente pasó a Pfizer $^{(1)}$.

\section{Las cirugías del rejuvenecimiento}

El fisiólogo vienés Eugen Steinach (figura 5) concluyó en 1920 que la ligadura unilateral del ducto deferente producía una hipersecreción hormonal después de que la producción secretora (de semen) de las gónadas cesaba. La operación de Steinach -tratamiento autoplástico- para adultos mayors, se volvió popular, habiéndose sometido a ella personajes como Sigmund Freud y William Butler Yeats, poeta irlandés y Nóbel de Literatura. Alejandro Lipschutz (1916) fisiólogo y antropólogo letón chileno -y el mismo Steinach- observaron hiperplasia de los cuerpos cavernosos de cobayas castradas e injertadas con un testículo. Aunque Steinach era un científico disciplinado (llamaba al tejido intersticial la "glándula de la pubertad"), esa operación a lo sumo producía algún efecto durante muy corto tiempo ${ }^{(20)}$.

Sergio Voronoff, un emigrante conde ruso ubicado inicialmente en París y luego en Algeria, hacía implantes de testículos de mico en humanos. Como era recibido por prestigiosas universidades donde dictaba conferencias y además logró publicaciones en algunas revistas, consiguió alguna notoriedad. Una comisión de científicos que lo visitó más adelante descalificó sus trabajos ${ }^{(20-22)}$.

Un médico que residía de la prisión de San Quintín (ubicada en una isla al frente de San Francisco y actualmente cerrada), de nombre Leo L. Stanley, realizó implantaciones heterologas de testículos de recién ejecutados en otros prisioneros, algunos de los cuales dijeron que se habían curado de una impotencia. Aparte de antiético, podríamos decir que el procedimiento era inoperante ${ }^{(1)}$.

Algunos cirujanos se volvieron ricos trasplantando testículos, que terminaron siendo de diversos mamíferos (venados, chivos, micos); se citan los cirujanos de Chicago Víctor Lespinasse y Frank Lidston ${ }^{(20-22)}$.

Ya mencionamos al falso médico John R. Brinkley (llamado "el doctor de las glándulas de cabra"), quien había comprado su diploma a una universidad pirata, la Eclectic Medical University de Kansas. En ese estado creó un centro de rejuvenecimiento a base de "xenotrasplantes", después de oír una conferencia de Voronoff en Chicago, acerca de sus implantes testiculares mico-hombre ${ }^{(20)}$. En Kansas no había micos, pero sí muchos chivos, así que hizo mucho dinero castrándolos y colocándolos en pacientes con disfunción eréctil, y luego para curar toda clase de síntomas masculinos. Como cualquier empresario, puso sucursales en diferentes estados de la Unión. Durante dos décadas ejerció en medio del descrédito de la comunidad médica, hasta que la Asociación Médica Americana tomó cartas en el asunto, le quitó la licencia médica y le cerró los centros. Fue también pionero de la radiodifusión, e incursionó en la política debido a su popularidad. Sus millones de dólares desaparecieron merced a numerosas demandas por

Figura 5. Eugen Steinach

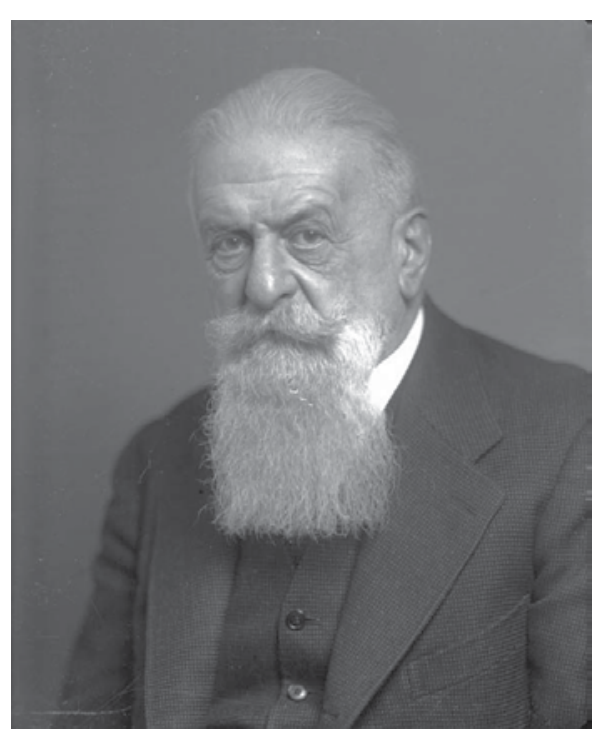


mala práctica, que perdió. Así, murió pobre y en desgracia. Su notoriedad logró, sin embargo, que luego se escribieran varios libros de tipo biográfico ${ }^{(10,22)}$.

\section{Investigación seria}

Al tiempo que existían estos charlatanes, hubo investigadores que realizaron estudios adecuados. Así se observó que en la orina de hombres normales hay algunas sustancias estrógenicas (de hecho las células de Leydig producen estriol) y que las mujeres también excretan andrógenos. Personajes como McGee, Fred Koch, Butenandt, Ruscika, Lacqueur y otros, lograron preparar extractos testiculares con cierta potencia y finalmente aislar, cristalizar y sintetizar una serie de esteroides sexuales, y además lograron esclarecer todos los pasos de la esteroidogénesis a partir de la molécula de colesterol y en núcleo esteroide del ciclopentano-perhidro-fenantreno ${ }^{(23,24)}$. Dichas investigaciones -y las que siguieron- se convirtieron en verdaderos aportes a la ciencia, por lo que consideramos que esto amerita un artículo especial.

\section{Referencias}

1. Jácome-Roca A. Historia de las Hormonas. Academia Nacional de Medicina, 2008, Bogotá.

2. Amaro-Méndez S. Breve historia de la endocrinología. Editorial CientíficoTécnica, La Habana, 1975.

3. Medvei VC. A History of Endocrinology. MTP Press Ltd. Lancaster, Lancashire, 1982.

4. Guthrie D. Historia de la Medicina. Reimpresión de 1a. Edición. Barcelona. Salvat editores, 1953.

5. Laìn-Entralgo P. Historia de la Medicina. la. Edición. Editorial Masson, Barcelona, 1978.

6. Jenkins JS. The Voice of the Castrato. Lancet. 1998; 351:1877-1881.

7. Melicow MM. Castrati singers and the lost "cords". Bull NY Acad Med. 1983; 59:744-64.

8. Nieschlag E, Nieschlag S. Testosterone deficiency, a historical perspective. Asian J Androl. 2014; 16 (2):161-168.

9. Wilson JD, Roehrborn C. Long-term consequences of castration in men: lesson from the Skopty and the eunuchs of the Chinese and Ottoman courts. J Clin Endocrinol Metab. 1999. 84:4324-31.

10. Morales A. The long and tortuous history of the discovery of testosterone and its clinical application. J Sex Med. 2013; 10:1178-1183.

11. Enerson OD. Franz von Leydig (biography) 2006. http://www.whonamedit. com/doctor.cfm/675.html

12. Bouin P, Ancel P. Recherches sur les cellules interstitielles du testicule des mammiferes, Arch de Zool Exp Gen. 1903; 1:437-523.

13. Jørgensen CB. John Hunter, A. A. Berthold, and the Origins of Endocrinology. Act His Sci Nat Med. 1971; 24:1-54.
14. Haas LF. Charles Edouard Brown-Séquard (1818-94). J Neurol Neurosurg Psych. 1998; 64:89.

15. Tattersall RB. Charles-Edouard Brown-Séquard: double-hyphenated neurologist and forgotten father of endocrinology. Diabet Med. 1994; 11:728.

16. Brown-Séquard CE. Note on the effects produced on man by subcutaneous injection of a liquid obtained from the testicles of animals. Lancet. 1889; 2:105-107.

17. Murray GR. Note on the treatment of myxedema by hypodermic injections of an extract of the thyroid gland of sheep. BMJ. 1891; 2:796-797.

18. Otero Ruiz E. Endocrinología y opoterapia, del receptor a la enfermedad. En "El Arte de Curar". http://www.afidro.com/arte_curar/p225/m_tex.html

19. Schwartz TB. Henry Harrower and the turbulent beginnings of endocrinology. Ann Intern Med. 1999; 131:702-706.

20. Setchell BP. The testis and tissue transplantation: historical aspects. J Reprod Immunol. 1990; 18:1.

21. Schultheiss D, Denil J, Jonas U. Rejuvenation in the early 20th century. Androl. 1997; 29: 351

22. Juhnke ES. Quacks and crusaders. The fabulous careers of John Brinkely, Norman Baker and Harry Hossey. Lawrence: University Press of Kansas, 2002.

23. Hoberman JM, Yesalis CE. The history of synthetic testosterone. Sci Am, 1995; $272: 76$.

24. Freeman E, Bloom DA, McGuire E. A brief history of testosterone. J Urol 2001; 165:371-373. 